\title{
Using paste backfill for stabilizing underground stopes at the Giant Mine remediation project
}

\author{
Bernie Ting \& David Stone \\ MineFill Services Inc \\ Kenny Ruptash \& Brandon Fabien \\ Nahanni Construction Ltd
}

SUMMARY: In 2018, a remediation program was executed to stabilize the underground voids near stopes that store arsenic trioxide waste at the Giant Mine in the Northwest Territories of Canada. The shapes of the voids were reconstructed through integrating multiple cavity monitoring system surveys. A number of mix recipes of paste backfill and selfconsolidating concrete (SCC) were designed with various bleeds, set times, uniaxial compressive strengths, and flow properties. Respectively, a total of $16,686 \mathrm{~m}^{3}$ and $53,389 \mathrm{~m}^{3}$ of SCC and paste were backfilled by gravity.

Keywords: reclaimed tailings, remediation, self-consolidating

\section{BACKGROUND}

Historic mining activities at the Giant Mine in the Northwest Territories of Canada left behind underground voids that resulted in a weakened crown pillar and surface subsidence. The subsidence becomes an immediate concern when it occurs in the proximity of public highways and nearby Baker Creek. Furthermore, some of the underground stopes store a large quantity of hazardous arsenic trioxide waste. The possibility of releasing the arsenic trioxide into the environment added further implications to the risk of unfilled voids. The objective of this remediation project was to stabilize an area in the C5-09 stope complex using backfill.

The C5-09 stope complex is located beneath three arsenic trioxide filled stopes. The void space in this area is complicated. The stopes were partially backfilled with rockfill and other unidentified materials. Some of the loose material was washed out to the lower levels of the mine during a large fluctuation in the mine water level in 2007. The ground conditions beneath the three arsenic stopes became unstable. The voids were undercut by a number of vertical raises, sub-levels, and draw points which present challenges as possible seepage or leakage during the backfill program. Sloughing from the hanging walls and footwalls, as well as pillar loading and ground noises had been observed over the past several years. Therefore, access to the C5-09 stope complex was limited.

Other challenges included the logistics of moving large quantities of fill materials to the relatively remote site, and the extreme cold temperatures during the winter season. In order to stabilize the area, an estimated volume of $54,084 \mathrm{~m}^{3}$ needed to be backfilled. The operation required a number of specialized paste recipes with varying set times, flowability, strength, and bleed water properties. 


\section{BACKFILL ENGINEERING}

One of the major challenges in this project was the lack of an accurate map for the underground. The shape and volume of the underground voids were reconstructed in $3 \mathrm{D}$ using a cavity monitoring system (CMS). In order to stabilize the area, and provide structural support to the nearby arsenic chamber, the plan was to use a combination of paste backfill and self-consolidating concrete (SCC).

Prior to backfill, remote cameras were placed at strategic locations to observe the progress and monitor possible leakage. Timber barricades were constructed to form a containment for the fill. The next step was to place a foam plug at the bottom of the void. This is shown in dark blue in Figure 1.

The bottom of the void was made of legacy backfill material, which had a wide variation of particle sizes. Therefore, a high slump (8 to 9 inches), relatively quick curing paste backfill was placed at the bottom of the void to build an impervious platform. Subsequently, the paste was increased to 10- to 10.5-inch slump to ensure good flowability. The bulk of the paste averaged $3 \%$ cement by weight, with a design strength of $100 \mathrm{kPa}$ after 28 days. The paste flowed by gravity creating a flat profile. When encountering a barricade, the cement content was increased to $7 \%$. The paste was placed in one-meter lifts every 24 hours until the paste level exceeded the height of the barricade to form a plug.

The main structural component is made of SCC, which had to be continuously poured to construct a $16,700 \mathrm{~m}^{3}$ monolithic structure. The SCC with a minimum of $12 \mathrm{MPa}$ UCS was delivered through five adjacent boreholes as shown in Figure 2. The placement was through boreholes in a ' $1,3,5,2,4$ ' sequence to maintain a fresh layer of material on the surface in order to avoid cold joints between pours. To minimize segregation and to place the SCC evenly, the backfill was delivered in tremie pipes with the bottom end held at the level of the freshly placed material.

After the SCC structure was completed, the operation switched back to paste backfill with a target UCS of $100 \mathrm{kPa}$ to top up the void.

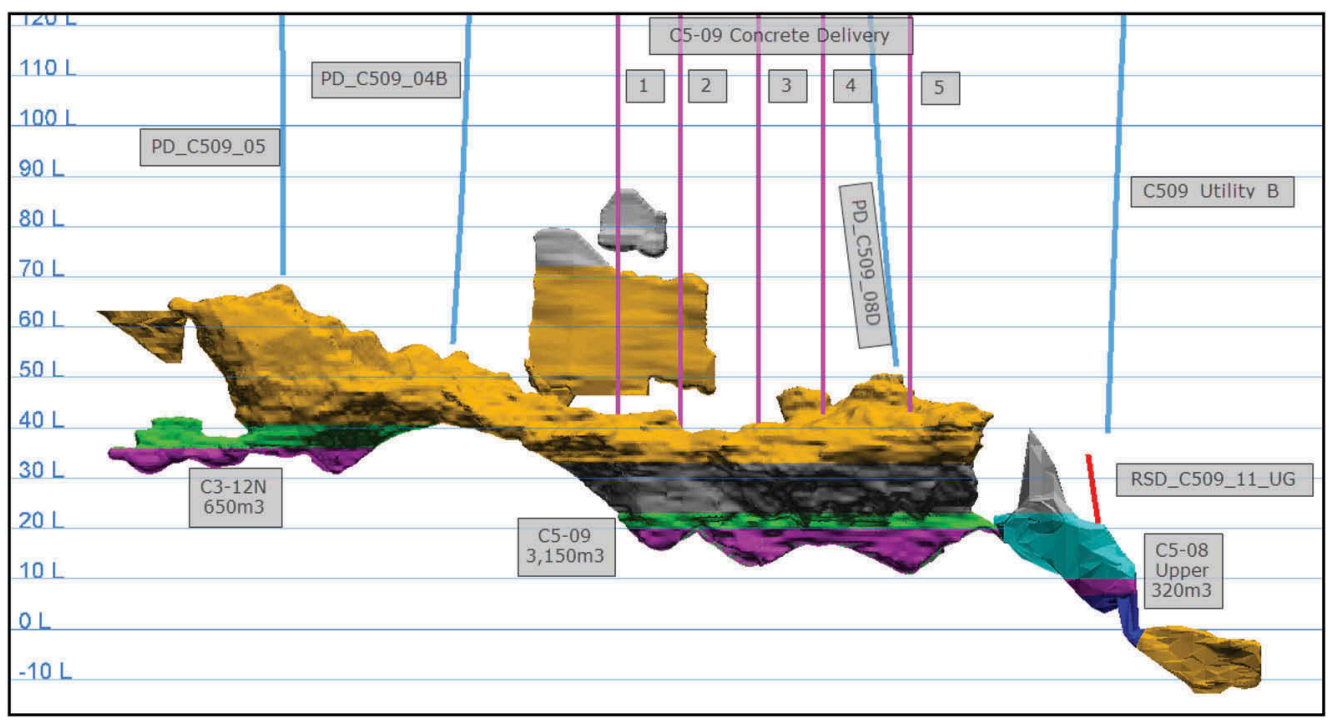

Figure 1. Underground void model reconstructed in 3D using CMS.

Source: C5-09 Stope Complex Work Plan (Nahanni Construction Limited). 


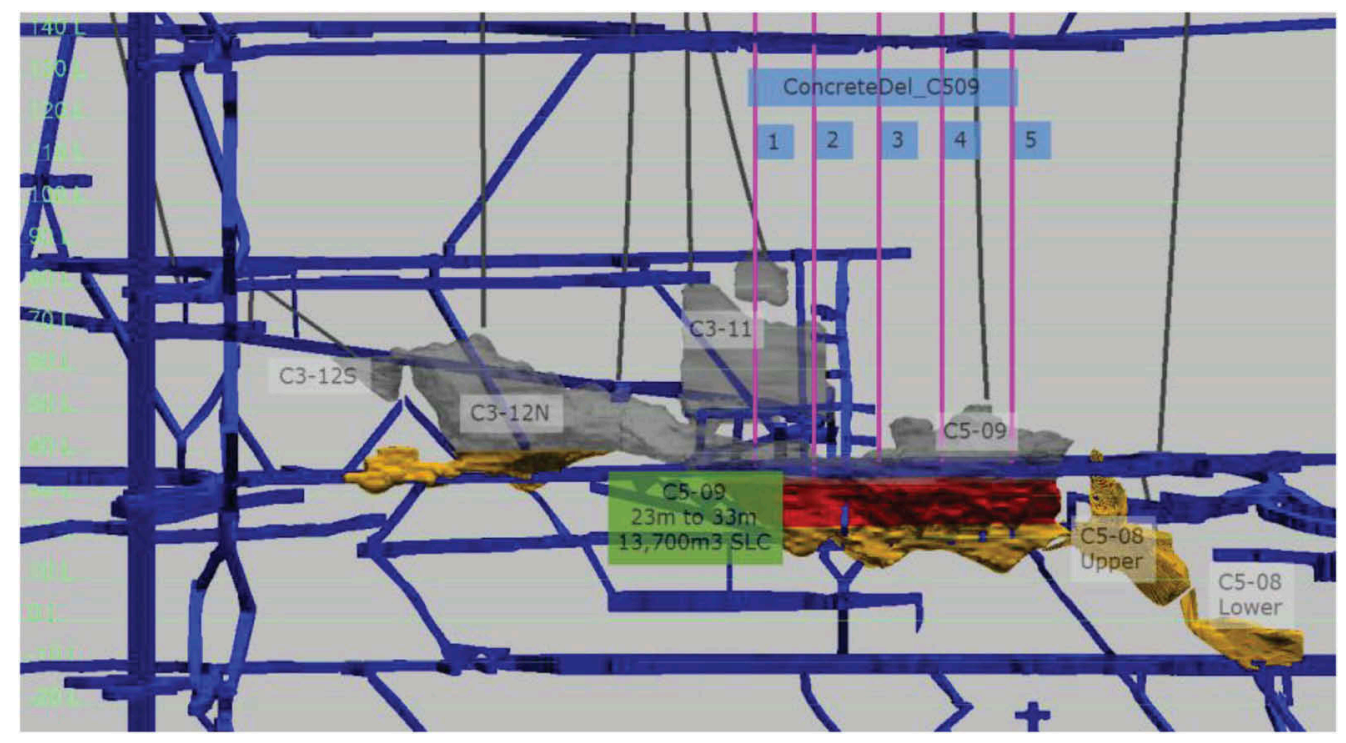

Figure 2. Underground void model reconstructed in 3D using CMS.

Source: C5-09 Stope Complex Plan (Nahanni Construction Limited).

\section{PASTE BACKFILL}

\subsection{Reclaimed tailings}

Prior to the project, gold tailings were sampled from the tailings pond. The particle size distribution (PSD) varied significantly both vertically and laterally in the tailings pond. In the samples, the fraction passing 20 micron varied between $5 \%$ to $53 \%$. In order to maintain the quality of the backfill, the tailings were reclaimed using a dozer, which scraped the tailings pond over a long distance. The tailings were screened to remove the foreign objects such as rocks and other organic materials. Then the piles were blended to reduce the fluctuations in tailings PSD.

\subsection{Paste mix design}

There were several criteria for paste design in this project. The uniaxial compressive strength (UCS) requirement was $100 \mathrm{kPa}$. Due to the expected fluctuations in tailings PSD, the target strength was set at $300 \mathrm{kPa}$ to ensure all the paste meets specification.

In order to minimize the stress on the cement transportation to Yellowknife, the main type of binder used in this project was a 90/10 slag cement. Compared to backfill materials made with Ordinary Portland Cement (OPC), slag cement has a lower early UCS but a higher 28day UCS. Nominally, the paste backfill operation used 120 tonnes of cement binder per day. When a quicker set time was required (such as when backfilling against a barricade), the cement content would be increased to improve early strength.

In addition, the paste needed to be a non-segregating material with a good flowability and minimal bleed water. An admixture was used to increase the solids content to $76 \%$ by weight while maintaining 10 to 10.5 inch slump. Figure 3 shows a summary of the UCS data during the first phase of the paste program. The fluctuation is a result of variation in PSD and cement content.

\subsection{Process description}

The paste backfill was pre-mixed using an auger-type mixer. The cement is added to the tailings based on the ratios in mix designs. The operators visually inspected the product to adjust 


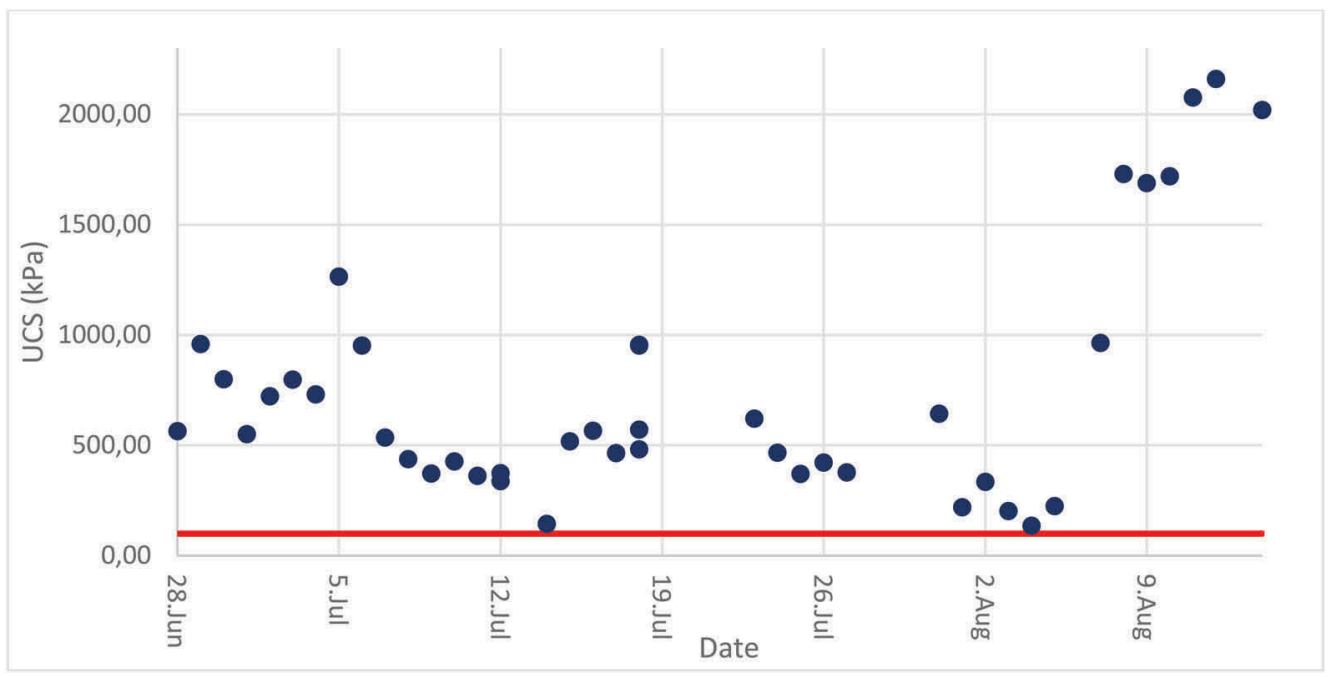

Figure 3. UCS variation in the first phase of the paste program.

Source: Nahanni Construction Limited QC database.

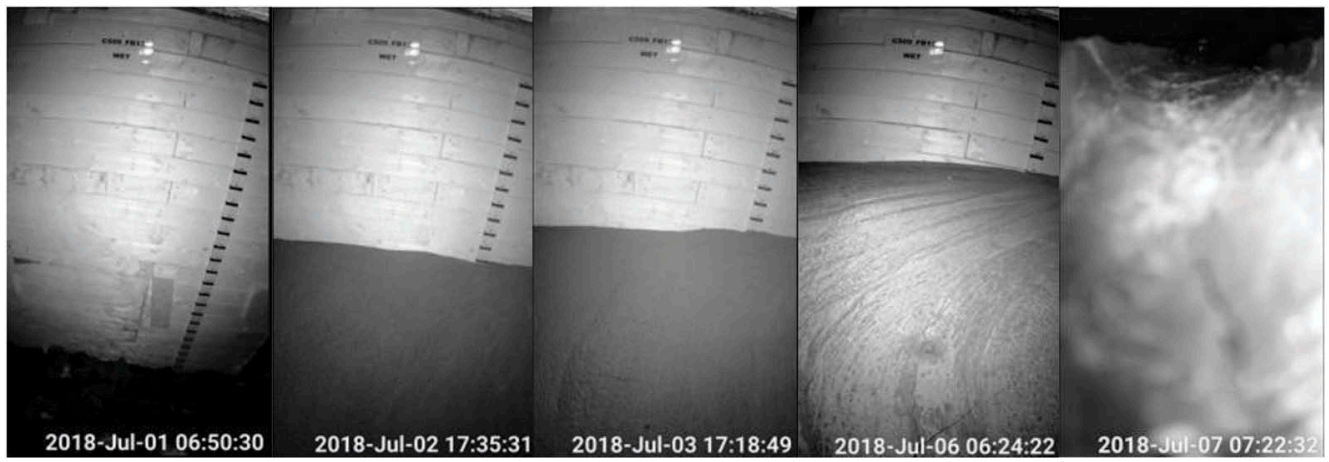

Figure 4. Monitoring paste backfill through remote camera.

Source: Nahanni Construction Limited underground camera record.

the mix water flowrate. A quality control (QC) technician conducted slump tests every hour to provide feedback to the operators and ensure the paste met the specification.

The paste was poured into a $40 \mathrm{~m}^{3}$ mixing tank through a passive screen, which screened out rocks or clay lumps. The mixing tank had a single shaft paddle mixer that further mixed the paste. From the tank, a peristaltic pump was used to load the paste into concrete trucks, which transported the paste to the boreholes for backfill placement by gravity.

Throughout the project, the monitoring crew tracked the progress through remote cameras, periodic CMS surveys, and paste level measurements using a plumb bob. Figure 4 shows the progress of the paste backfill by looking at the paste level against the marking on the post in the background.

In total, $53,389 \mathrm{~m}^{3}$ of paste backfill was placed, with a maximum daily backfill of $1,750 \mathrm{~m}^{3}$ per day. 


\section{SELF-CONSOLIDATING CONCRETE AS BACKFILL}

\subsection{Sourcing the aggregates}

The SCC consisted of two sources of locally available aggregates (ACE and Det'on Cho), reclaimed tailings, and cement binder. The rationale behind mixing multiple types of aggregate with tailings was to produce a desirable particle size distribution. More importantly, no local source of aggregate was sufficient in quantity for what was required in this project.

Comparing to the paste operation, the SCC program used more cement per day. At $600 \mathrm{~m}^{3}$ per day of backfill, the operation required 225 tonnes of cement. At times, only 160 tonnes were delivered in a day, so the production rate had to be reduced to maintain a continuous pour.

\subsection{SCC mix design}

The SCC has a target strength of $12 \mathrm{MPa}$. The material was first designed at the on-site laboratory. The material was subjected to slump flow, segregation, bleed water and UCS tests in accordance to procedures outlined in the ASTM standards.

To examine the curing condition of the SCC, the maximum temperature and thermal gradient in the stope were calculated using computer simulation. Subsequently, full scale trial batching was carried out, and the SCC was placed on the surface to test the flowability as shown in Figure 5.

To direct the placement through the five boreholes, tremie pipes were lowered to the bottom. The pipes were clamped on the steel platform on the surface. Using underground cameras, the pipes were elevated with hydraulic jacks as shown in Figure 6. As the level rises, the pipes were trimmed to keep the chute low enough for the truck to unload into.

Next to the tremie pipes, two extensometers with temperature sensors were lowered and became embedded in the SCC when the backfill was completed. Figure 7 below shows an image of the arrangement taken from an underground camera.

The target daily backfill volume was $600 \mathrm{~m}^{3} /$ day, which was limited by the capacity of transporting cement to the site. When necessary, the production rate would be reduced to maintain a fresh layer of SCC on the surface. This was to minimize the possibility of forming a cold joint. Due to logistics, the operation was later forced to switch binder from slag cement to a fly ash cement. In anticipation of the switch, the team quickly designed another mix recipe that met the design criteria.

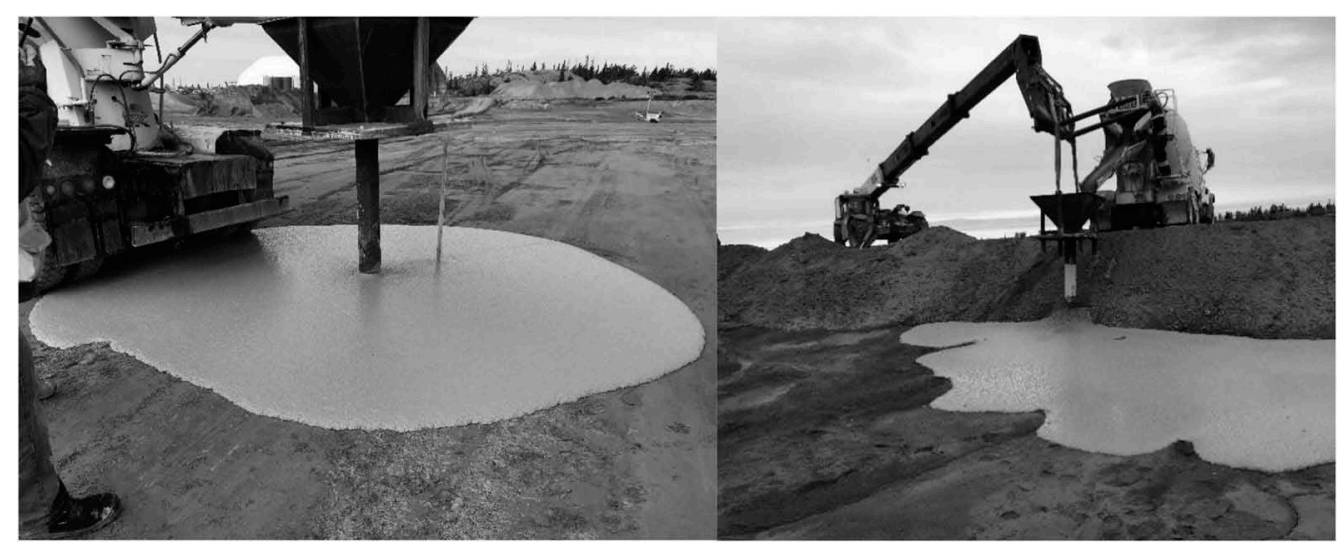

Figure 5. Full scale SCC trial batching on the surface.

Source: MineFill Services project database. 


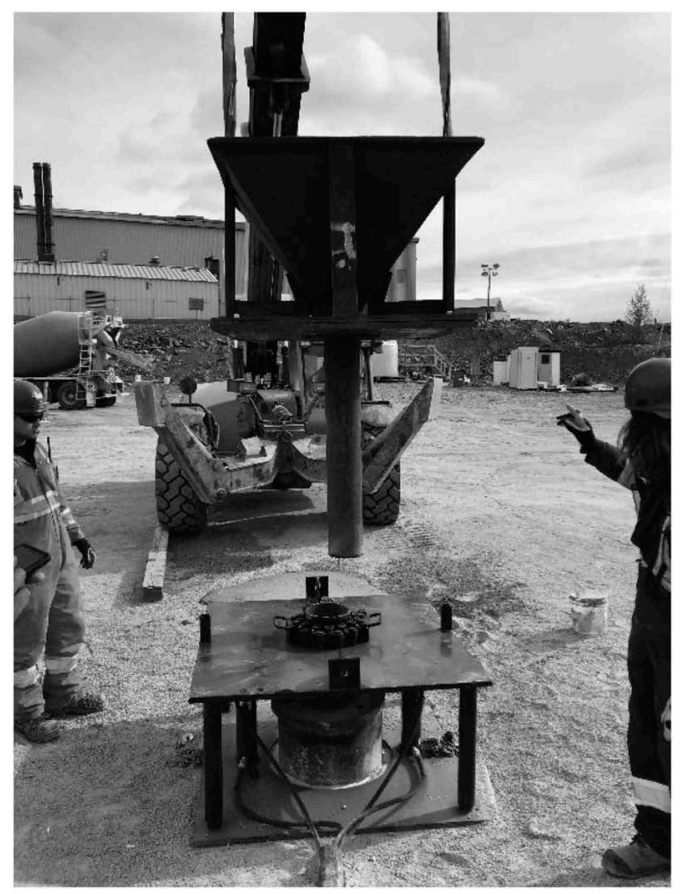

Figure 6. Hydraulic jacks for raising the tremie pipes.

Source: MineFill Services project database.

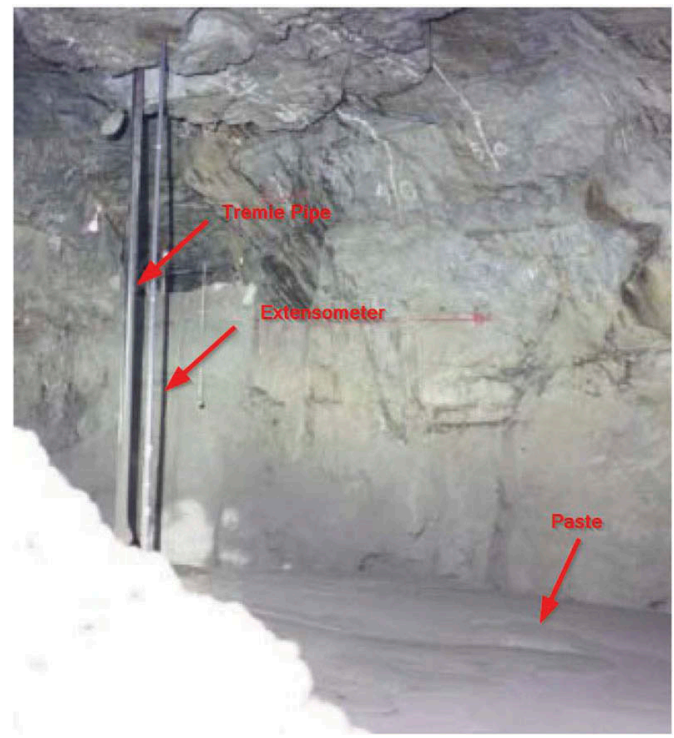

Figure 7. Image of the tremie pipe and extensometer taken with underground camera. Source: Nahanni Construction Limited underground camera record. 


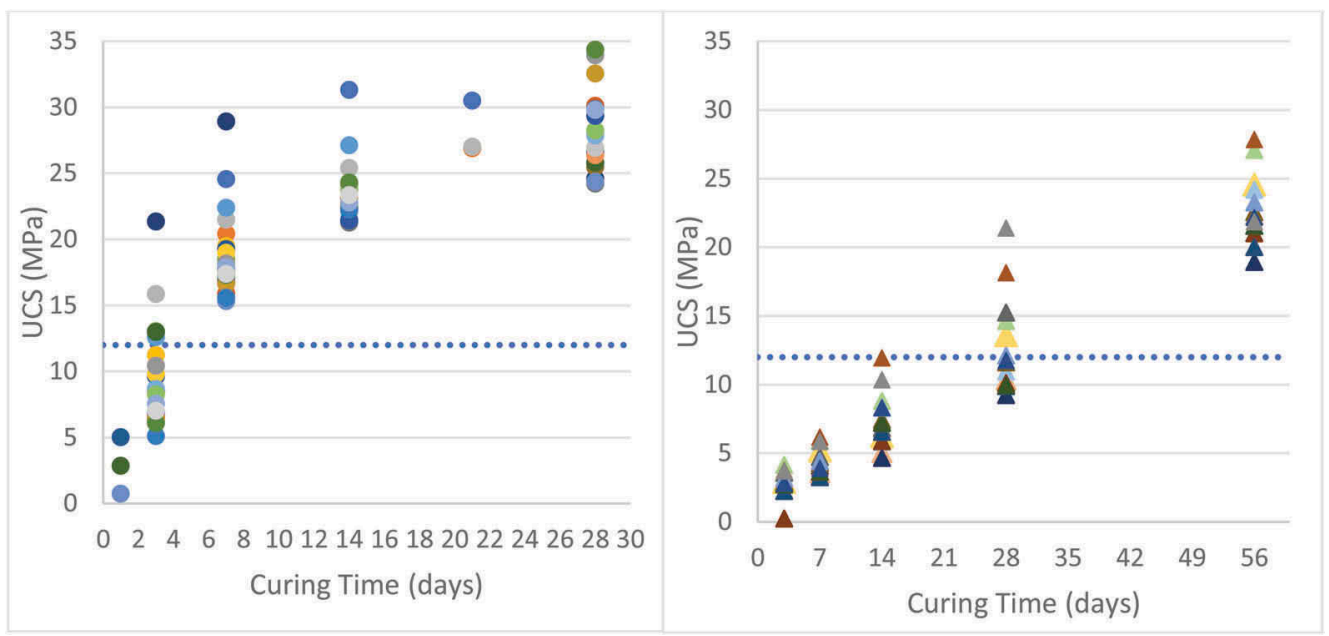

Figure 8. UCS of SCC made with slag cement (left) and fly ash cement (right).

Source: Nahanni Construction Limited QC database.

During the continuous backfill, a sample of the SCC was collected at the borehole every 12 hours. The material was cast in 4 inch diameter by 8 inch high cylinders for UCS testing. As shown Figure 8, all the materials exceeded the 12 MPa UCS. As expected, the SCC made with slag cement developed a noticeably higher strength than that of with fly ash cement.

\subsection{Process description}

The SCC was produced using a conventional concrete batch plant. The aggregate bins ratioed the materials onto a conveyer belt using a loss-in-weight mechanism. The plant loaded the aggregates, cement, water, additives into concrete trucks. When the trucks arrived at the borehole area, they were parked in order to extend the mixing time for additional five minutes. After mixing was complete, the operator unloaded the SCC into the borehole.

In the SCC phase of this project, the daily consumption of cement varied between 110 to 310 tonnes per day. The process used between 383 to 1200 tonnes per day of locally sourced aggregate. The variation was largely dependent on the availability of the cement. Overall, a total of $16,686 \mathrm{~m}^{3}$ of SCC was backfilled with a maximum backfill placement rate of SCC of $814 \mathrm{~m}^{3}$ per day.

\section{BACKFILLING IN COLD WEATHER CONDITIONS}

Due to the challenge of receiving a sufficient quantity of cement, the project continued into December of 2018. The ambient temperature in Yellowknife lowered to an average of -17 degree Celsius and reached as low as -30 degree. Extreme cold temperatures can cause freezing on the equipment and particularly water lines. Furthermore, the freezing temperatures had a dramatic impact on the rate of cement hydration. There are several strategies for operating with paste backfill in these extremely low temperature conditions. Considering the logistical challenges and the locally available resources, the most reliable strategy was to heat the mix water. A simplified thermal calculation based on the heat transfer equation determined that the mix water needed to be above 25 degree Celsius for the paste to be above the freezing point.

In October, a diesel-powered water heater was brought to site and commissioned. Eventually, the paste approached the freezing temperature without the heater. As shown in Figure 9, the paste started to freeze and became less flowable. 


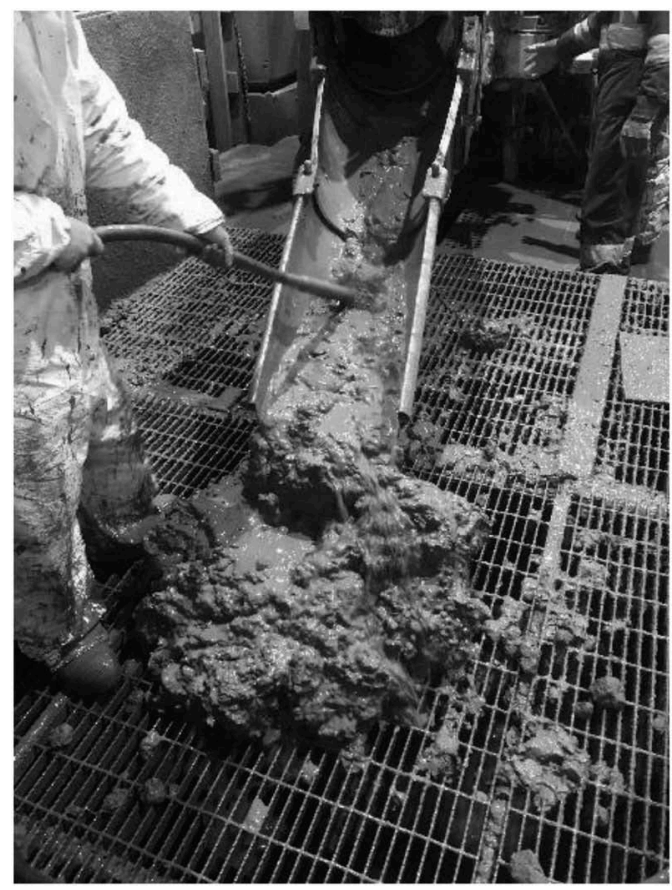

Figure 9. Frozen paste caught on the screen.

Source: MineFill Services project database.

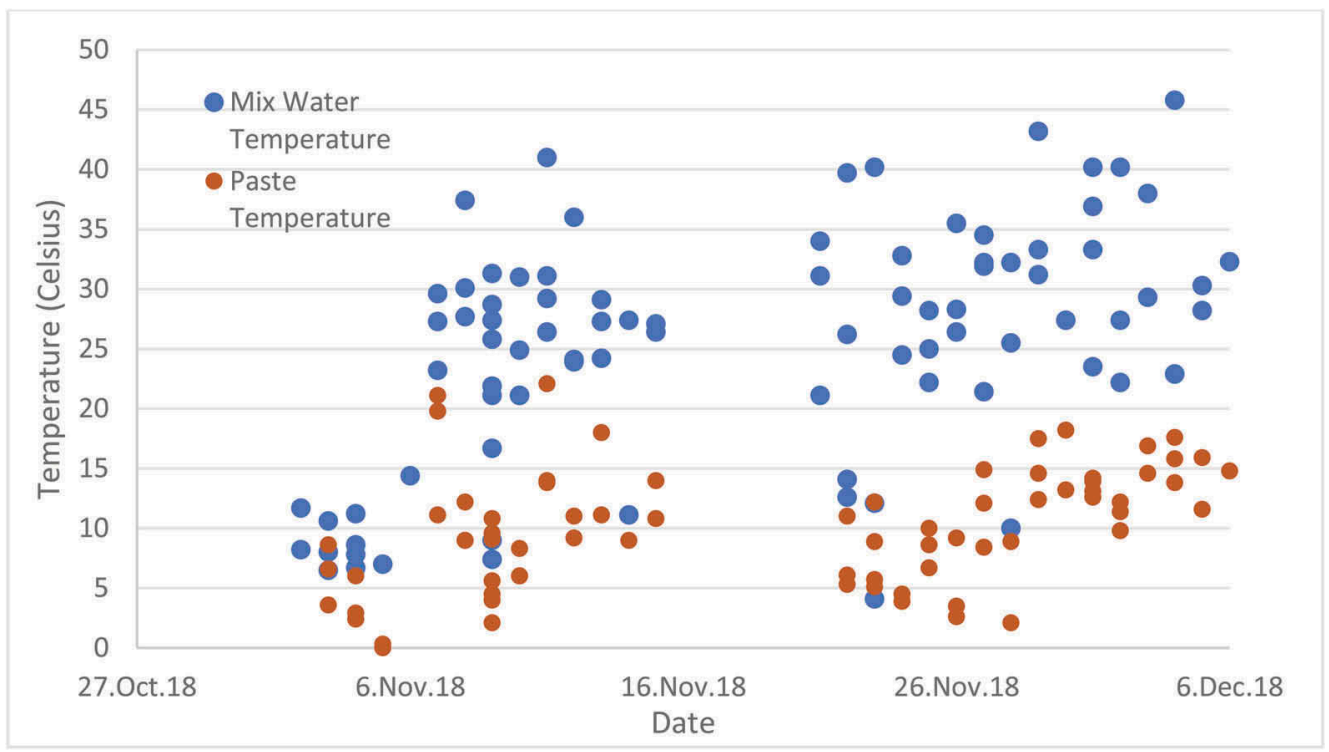

Figure 10. Paste and water temperature.

Source: Nahanni Construction Limited QC database.

The temperatures of the mix water and paste were measured multiple times every day as shown in Figure 10. The very low paste temperatures triggered the use of the water heater. Even though the paste only contained 25 weight percent of water, the high heat capacity 
helped bring the overall paste temperature to above freezing. Note the fluctuation in the temperatures was a function of the time in the day and the rate of backfill production.

As with other cold weather operations, the cold weather required additional maintenance on the equipment to periodically clear frozen material. Winterizing the plant allowed the project to continue. The voids were filled to the collar of the boreholes and the project was completed on Dec 11th.

\section{CONCLUSION}

A combination of paste backfill and SCC was used to stabilize underground voids at the Giant Mine. CMS surveys were used to reconstruct the shape of the areas that needed to be backfilled. A number of paste and SCC mix recipes were designed with various flowability, set times, UCS, and bleed properties.

A continuous paste plant and a concrete batch plant were installed to produce the backfill materials, which were transported by truck to the boreholes. By gravity, the paste and SCC were placed underground, and totalled $16,685 \mathrm{~m}^{3}$ and $53,388 \mathrm{~m}^{3}$ respectively.

The process was monitored using remote camera, CMS surveys, and plumb bob measurements. Despite the challenges such as the lack of an accurate map of the voids, unstable underground conditions, extreme cold temperatures, and logistics of transporting materials to the site, the project was successfully completed on Dec $11^{\text {th }} 2018$.

\section{ACKNOWLEDGEMENTS}

The authors would like to thank Garrett Whipp, Steve Clayton, Public Services and Procurement Canada, and Golder Associates for their support in this project. The authors also want to express their gratitude to the entire crew who devoted their best effort to complete this challenging project.

\section{BIBLIOGRAPHY}

ASTM 2018, C31 Making and Curing Concrete Test Specimens in the Field. ASTM International. West Conshohocken.

ASTM 2018, C39 Compressive Strength of Cylindrical Concrete Specimens. ASTM International. West Conshohocken.

ASTM 2015, C143 Slump of Hydraulic-Cement Concrete. ASTM International. West Conshohocken.

ASTM 2016, C940 Expansion and Bleeding of Freshly Mixed Grouts for Preplaced-Aggregate Concrete in the Laboratory. ASTM International. West Conshohocken.

ASTM 2014, C940 Slump Flow of Self-Consolidating Concrete. ASTM International. West Conshohocken.

ASTM 2010, D2216 Laboratory Determination of Water (Moisture) Content of Soil and Rock by Mass. ASTM International. West Conshohocken.

NCL 2018. Giant Mine C5-09 Remediation Project Quality Control Database. Nahanni Construction Limited. Yellowknife, Northwest Territories, Canada.

NCL 2018. Giant Mine C5-09 Stope Complex Plan: Revision 3. Nahanni Construction Limited. Yellowknife, Northwest Territories, Canada. pp. 28. 